\title{
CFD ANALYSIS OF THE FLOW CHARACTERISTICS OF PARABOLIC NOZZLE BY CHANGING THE SHAPE OF NOZZLE EXIT
}

\author{
A. ADAIKALARAJ ${ }^{1}$, M. SUNDARARAJ ${ }^{2} \&$ M. SYEDHALEEM ${ }^{1}$ \\ ${ }^{1}$ Assistant Professor, Department of Aeronautical Engineering, Bharath Institute of Higher
} Education and Research, Chennai, Tamil Nadu, India

${ }^{2}$ Head and Associate Professor, Department of Aeronautical Engineering, Bharath Institute of Higher

Education and Research, Chennai, Tamil Nadu, India

\begin{abstract}
This paper deals with new design of nozzles which can be used in Aerospace applications called as parabolic nozzles. Parabolic nozzles are actually mechanical devices which produces mechanical energy by converting the thermal and pressure energy produced as a result of combustion. This project aims at providing the flow characteristics of parabolic nozzle by changing the shape of the exit area. The analyses were further extended by changing the pressure values. The analyses processes were carried out using Computational Fluid Dynamics software ANSYS CFX. The result of this study showed that the working nature of the nozzle while changing its exit shape and also the pressure.

KEYWORDS: Parabolic Nozzle, Pressure \& Exit Shape
\end{abstract}

Received: Mar 14, 2019; Accepted: Apr 04, 2019; Published: May 05, 2019; Paper Id.: IJMPERDJUN201964

\section{INTRODUCTION}

A nozzle is a mechanical device of varying cross section which controls the flow characteristics and the direction of the fluid may be water or air flowing through it. Nozzle can be used in rocket engines to expand and accelerate the gases produced at a result of combustion. When the fluid flows through the nozzle, the exit velocity will be greater when compared with the inlet velocity. Nozzles actually works based on the law of conservation of mass. That is the rate of change of mass equals to product of density, area and velocity. The revolution in aerospace propulsion was increased during world war. Advanced rocket propulsion systems actually requires high performance nozzle. Those nozzles need to be work efficiently on all working altitudes. Most of the nozzles failed to satisfy the altitude compensating effect or else they are extremely difficult to manufacture. Parabolic nozzles are currently used for all aerospace applications. The main drawback of these nozzles is decrease in efficiency with increase in altitude. This occurs due to the process of separation of the combustion gases. For conventional bell nozzles, loss mechanisms can be categorized in to three,

- Geometric or divergence loss

- Viscous drag loss

- Chemical kinetic loss.

Geometrical loss occurs when a portion of nozzle exit flow is directed away from the nozzle axis. Viscous drag loss is due to the drag force produced at the nozzle wall by the effects of a viscous high speed flow. The last 
category of loss mechanism is due to finite rate chemical kinetics. The rapidly accelerating nozzle flow does not permit time for the gas to reach full chemical equilibrium. This project deals with the study of flow characteristics of parabolic shaped nozzle when it is put in to real conditions. The flow parameters and contours were observed and recorded in this paper.

\section{MODELLING AND SIMULATIONS}

To analyze the nozzle, the following steps were performed in Computational Fluid Dynamics: Modelling, Meshing, Pre-processing, Solution, Post-processing. A parabolic nozzle of length 19 feet was selected for our study with the exit shape as square, elliptical and circular with horizontal dimension as 11 feet 7 inches. The design used for analysis was designed using CATIA V5 software packages. The figure 1 shows the various configurations of nozzles.
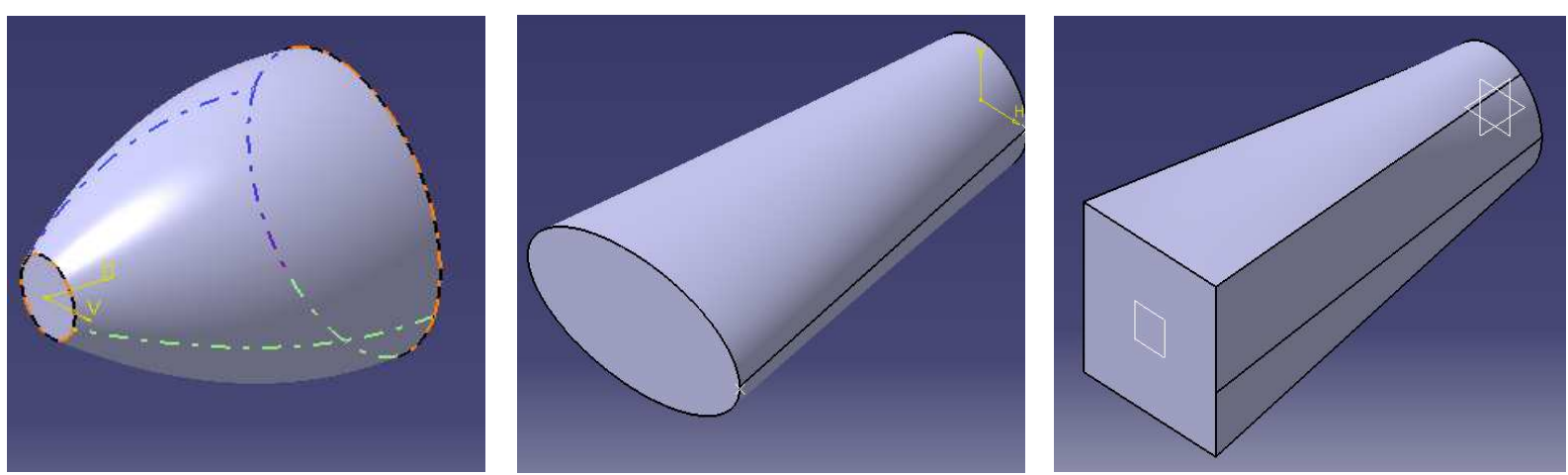

Figure 1: Various Configuration of Nozzles

After modelling of the nozzle, meshing was done using ICEMCFD software. The accuracy of the contours depends on the fineness of the mesh. To capture the exit flow of the nozzle, the exit region was covered with denser mesh.

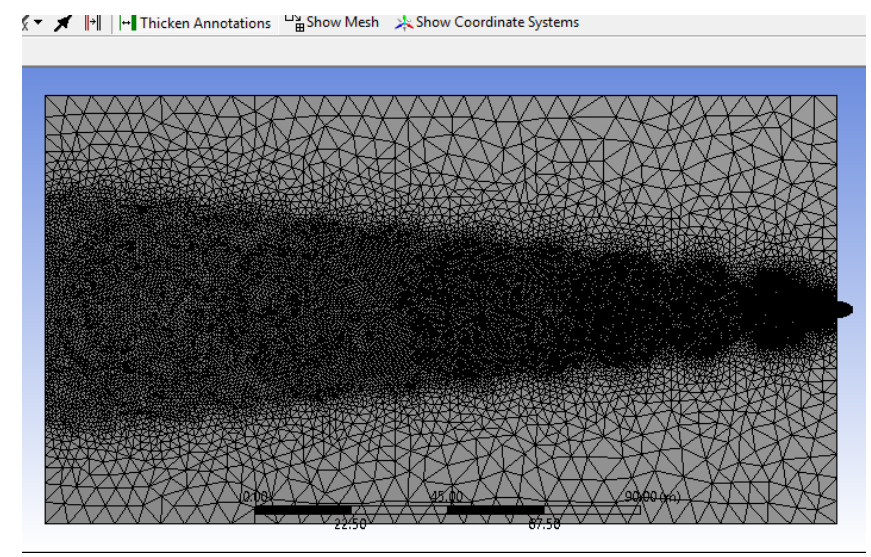

Figure 2: Discretized Model of Nozzle

\section{RESULTS AND DISCUSSIONS}

Pre-processing steps were done in ANSYS CFX. The meshed model was imported in to the simulation region for analysis. The boundary conditions were stated. Inlet pressure, inlet temperature and the turbulence models were selected. The flow parameters were observed and recorded. 
Nozzle by Changing the Shape of Nozzle Exit

\section{Velocity Contour}

At pressure $=3 \mathrm{bar}$

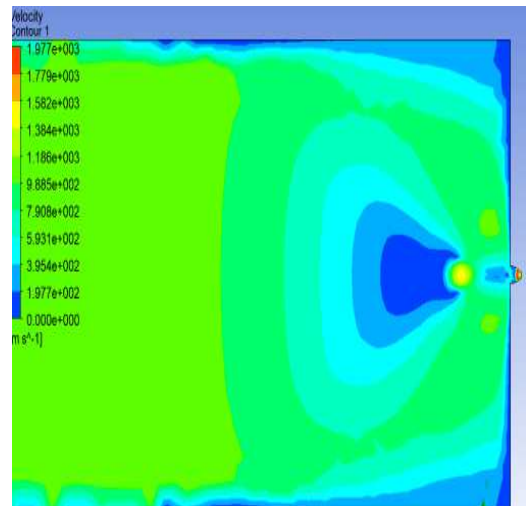

Circular

At pressure $=7$ bar

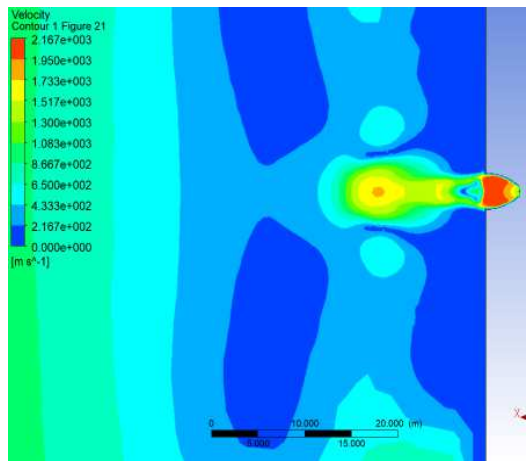

Circular

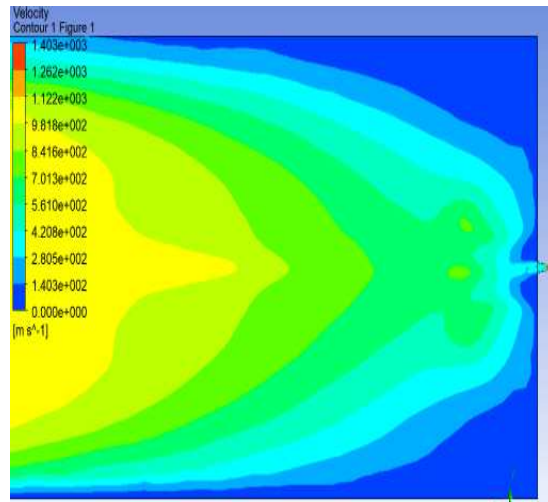

Elliptical

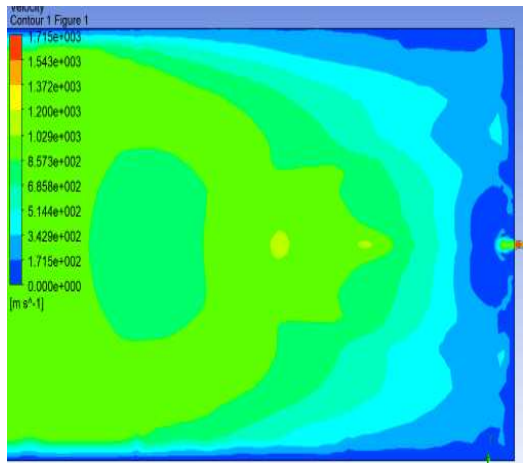

Elliptical

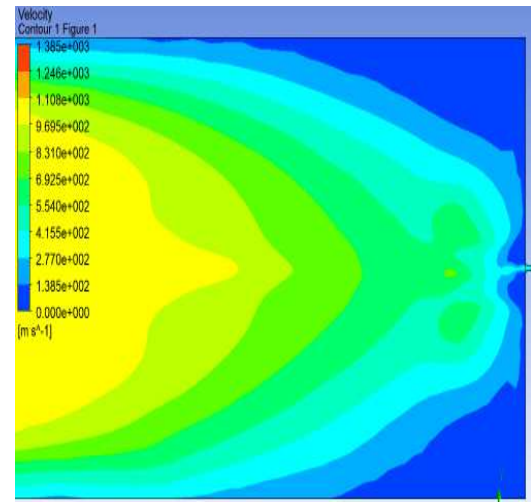

Square

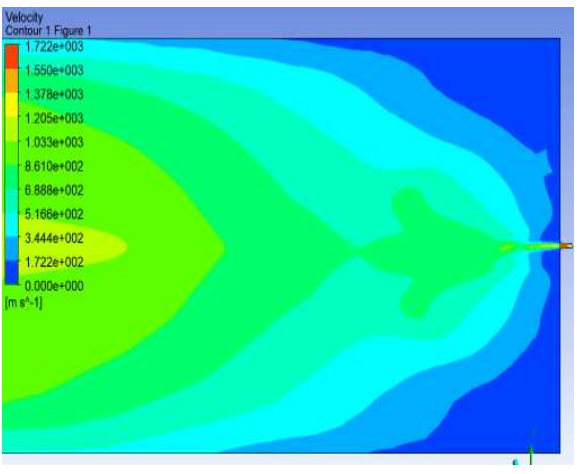

Square

Figure 3: Velocity Contour for Various Nozzle Configurations

\section{Pressure Contour}

At pressure $=3$ bar

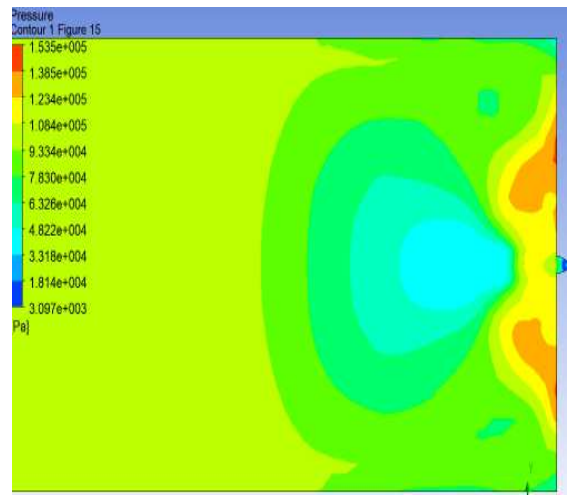

Circular

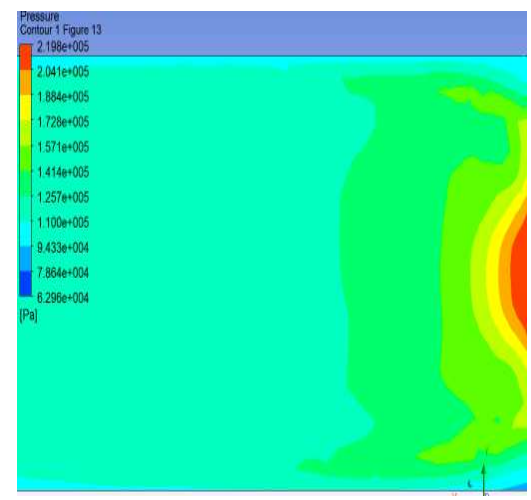

Elliptical

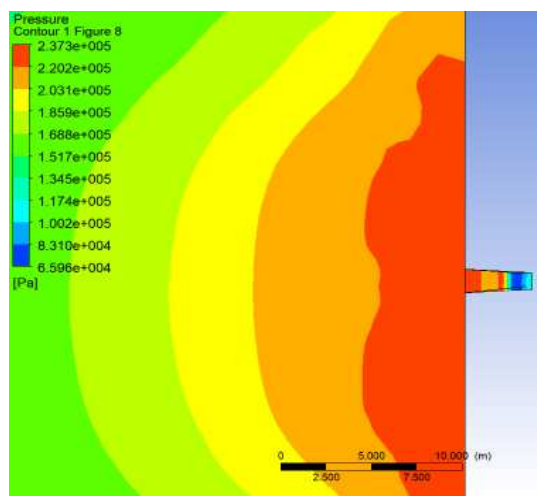

Square

At pressure $=7$ bar 


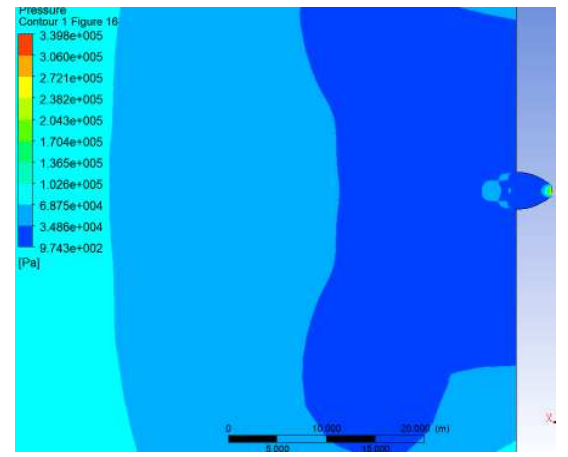

Circular

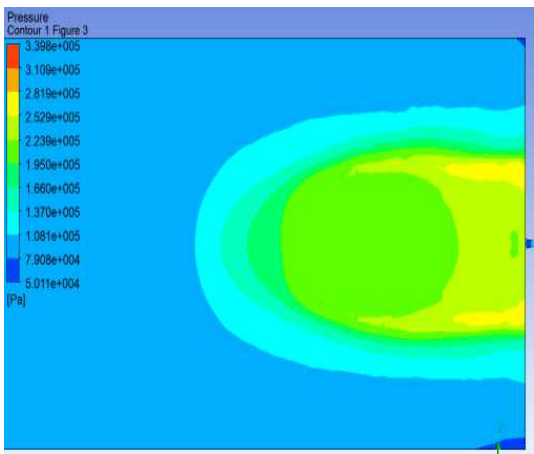

Elliptical

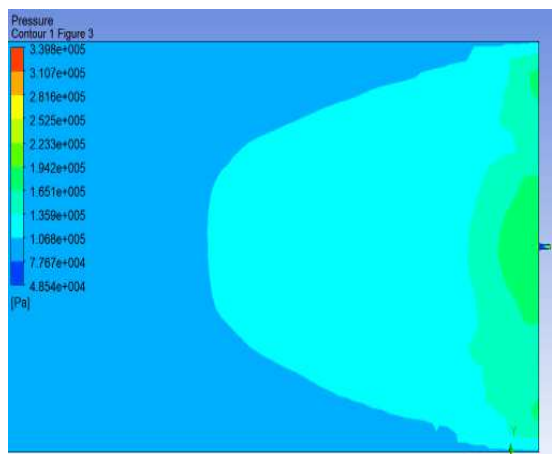

Square

Figure 4: Pressure Contour for Various Nozzle Configurations

\section{Temperature Contour}

At pressure $=3$ bar

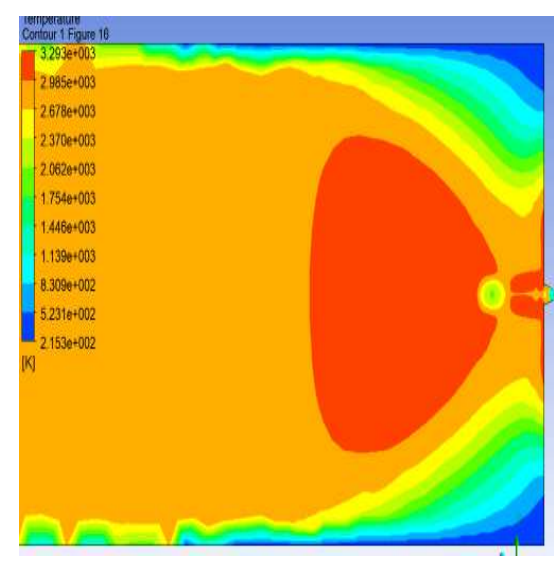

Circular

At pressure $=7$ bar

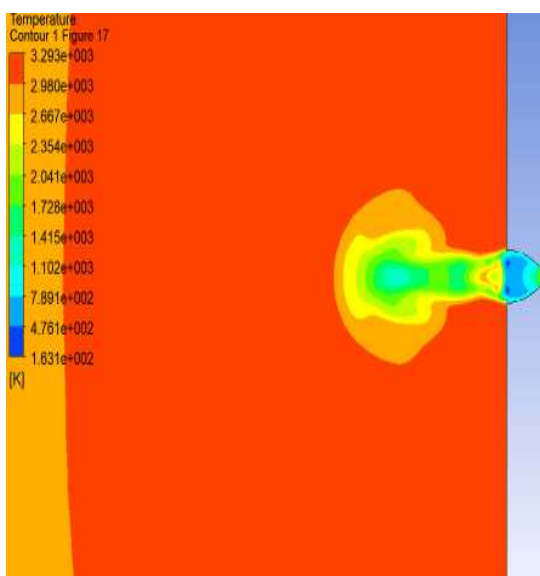

Circular

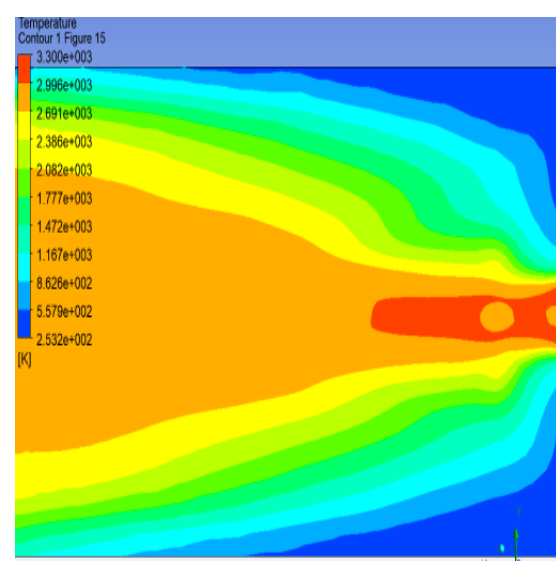

Elliptical

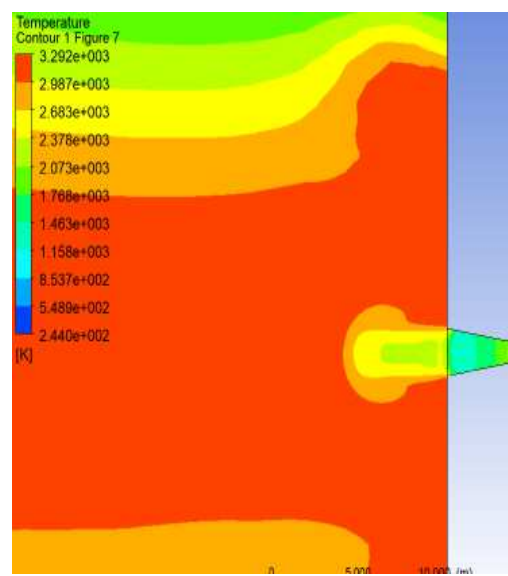

Elliptical

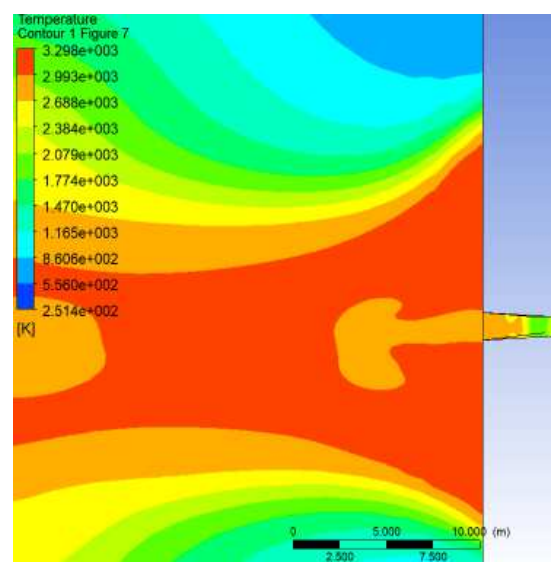

Square

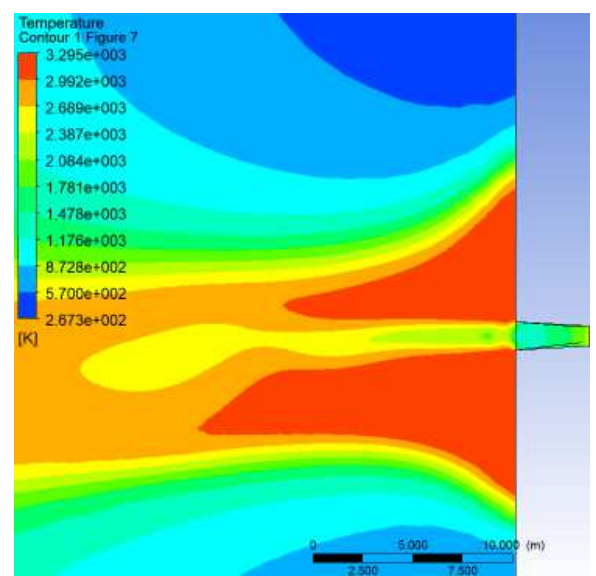

Square

Figure 5: Temperature Contour for Various Nozzle Configurations 


\section{Mach Number Contour}

At pressure $=3 \mathrm{bar}$

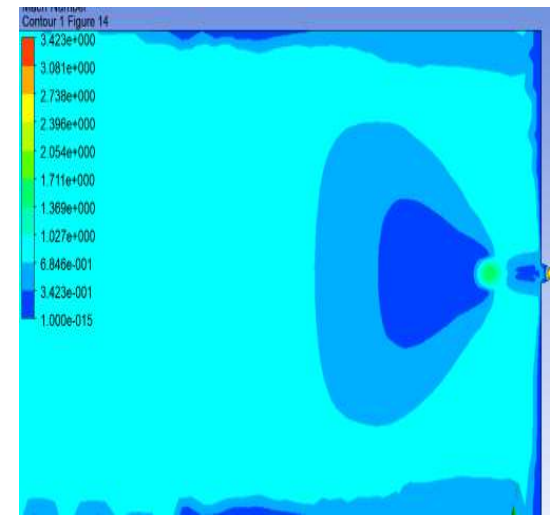

Circular

At pressure $=7$ bar

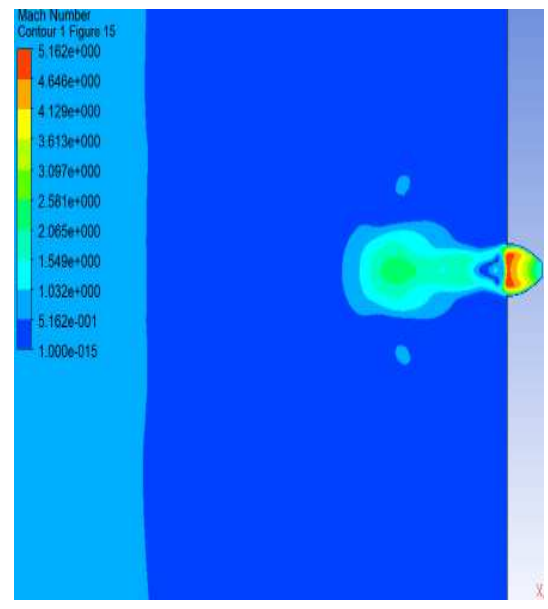

Circular

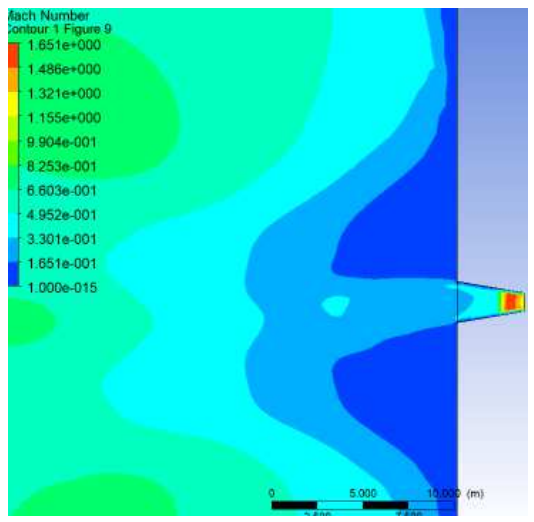

Elliptical

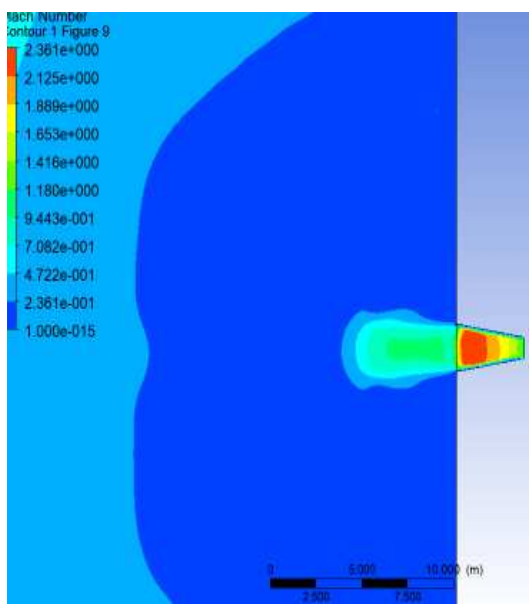

Elliptical

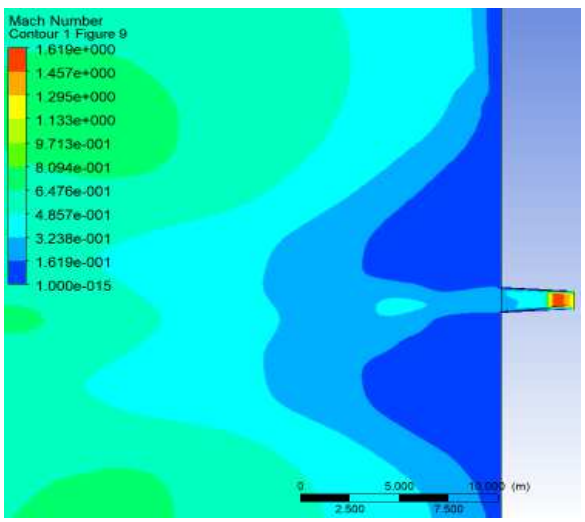

Square

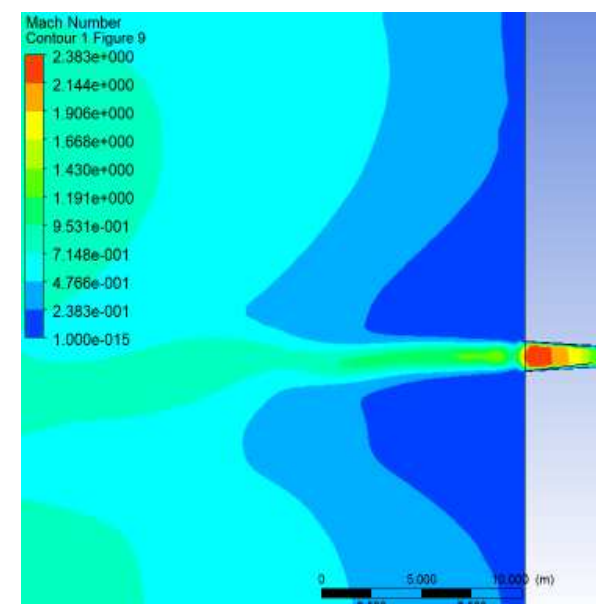

Square

Figure 6: Mach Numbers for Various Nozzle Configurations

\section{CONCLUSIONS}

The results obtained by Computational Fluid Dynamics are almost similar to the theoretical results. The pressure contours, velocity contours and temperature contours were compared among the three different configurations. CFD considers the factors such as boundary layer effects, shock waves and also the velocity component changes and so on. Those details help to learn about the performance of the nozzles.

\section{REFERENCES}

1. Erich Besnard, Hsun Hu Chen, Ton Mueller, Design Manufacturing and test of a plug rocket nozzle, Mechanical and Aerospace engineering department, California State University, Long Beach.

2. J.J, Korte, Parametric Model of an Aerospike Rocket Engine, NASA Langley Research Centre, Hampton, Virginia.

3. Klaus W.Gross, Performance Analysis OfAerospike Rocket Engines. 
4. Moorthy, C. V., Srinivas, V., Prasad, V. V. S. H., \& Vanaja, T. (2017). Computational analysis of a CD nozzle with 'SED' for a rocket air ejector in space applications. 7 (1). Pp 53, 60.

5. Brandon Lee Denton, Design And Analysis of Rocket Nozzle Contours For Launching Pico-Satellites, Department of Mechanical Engineering, Kate Gleason College Of Engineering, Rochester Institute Of Technology, NY.

6. MaciejMatyka, Prandtl-Meyer Expansion Wave, Computational Physics Section of Theoretical Physics, University of Wroclaw.

7. John Cipolla, AeroRocket and Warpmetrics http://aerorocket.com/MOC/MOC.html

8. Chang Hui Wang, Yu Liu, Li-Zi Qin, Aerospike Nozzle Contour Design and Its Performance Validation, Beijing University Of Aeronautics and Astronautics, Beijing. 